\title{
LA CULTURA VASCA Y LOS «ENCUENTROS POSIBLES»
}

\author{
Natalia Vara Ferrero \\ (Universidad del País Vasco)
}

Edurne Portela, El eco de los disparos. Cultura y memoria de la violencia, Barcelona, Galaxia Gutenberg, 2016, 224 pp. ISBN: 9788416734115

«Me interesan esas representaciones que nos ayudan como lectores o espectadores a imaginar, pensar y sentir nuestra propia relación con los hechos no desde la denuncia moral o la ideología, sino desde espacios afectivos de incomodidad e incertidumbre» (146); la incomodidad, el deseo de importunarnos en nuestra fácil y cómoda indiferencia es el objetivo que persigue El eco de los disparos, un texto de complicada clasificación que ha tenido un amplio eco en los medios de comunicación nacionales, contribuyendo a avivar el de por sí complicado debate sobre la violencia en el País Vasco. Riguroso, arriesgado, ameno y, en cierta manera, provocador, este libro invita al lector a revisar los ecos de esos disparos que determinaron durante décadas las dinámicas de convivencia de la sociedad vasca, pero sobre todo instiga a reflexionar sobre las relaciones y las manifestaciones culturales que conformarán nuestro futuro inmediato, un futuro que no debería cerrarse en falso y no debería ceder a un silencio que resulta ya demasiado largo. Lo comprobamos desde el sorprendente punto de arranque del discurso, los recuerdos de los juegos de la infancia en un cementerio francés, durante la visita que hace la autora con la familia a los «hombres barbudos», visita que deberá callar; y lo confirmamos nuevamente con el punto final, titulado «Un final por venir», la apuesta aún por realizar, una conversación abierta y sosegada con alguien que tiene una perspectiva diferente a la autora, una conversación en la que el nombre de la interlocutora no puede ser dicho y que deja bien claro que la aparente placidez social del presente no es sino un engaño revestido de más silencio. Así, el silencio en la sociedad vasca se muestra en toda su extensión temporal y espacial, un silencio que ha impedido tanto el diálogo como el conocimiento de los otros. 
El eco de los disparos es un libro de género indeterminado, un ensayo académico sui géneris que rompe nuestras expectativas, reflejo formal de la enorme complejidad del tema que trata y de la diversidad de perspectivas y dimensiones desde el que este se puede abordar. Lo que arranca como el diagnóstico de una generación que convive con una violencia cotidiana y normalizada (e incluye escogidos fragmentos de intrahistoria personal y ajena, así como pinceladas de Historia oficial), continúa sólidamente sin escatimarnos pasajes centrales que funcionan como un ensayo de análisis cultural. En esta particular articulación, la autora une su propio proceso de aprendizaje y maduración con el desarrollo de un análisis riguroso, aunque también subjetivo y selectivo. De este modo, ensancha, desde las primeras páginas y sin caer en el desaliento, los límites de lo académico para ofrecernos un texto no convencional cuyas distintas facetas se alimentan entre sí: lo autobiográfico sustenta las reflexiones sobre la violencia, sus análisis críticos reclaman un proceso de conocimiento y reflexión individual y colectivo que pueda servir a una futura sociedad vasca. La porosidad entre las dimensiones del discurso logra que, lejos de funcionar exclusivamente en una dimensión académica, aluda a la conciencia del lector, para obligarlo a pensar y a pensarse en relación con su propio cultural, sus ideas y afectos.

Partiendo de la Ética de Baruch Spinoza y de su teoría de los afectos, Portela relaciona los afectos positivos y los negativos con la capacidad que tiene la imaginación humana para relacionarnos con el otro. Por esa razón la imaginación se entiende como un elemento de enorme importancia, pues es la clave de nuestro conocimiento de los otros. Se trata del elemento que guía nuestros afectos como individuos y como sociedad y ese es precisamente el aspecto que interesa a Portela para desarrollar su investigación. Si sólo somos capaces de imaginar al otro como intruso que nos amenaza como individuos y como grupo, únicamente podremos entenderlo como enemigo, y la indiferencia que nos aísla y protege no sólo nos convertirá en testigos, nos hará también cómplices de la violencia. Sin lugar a dudas, una «de las consecuencias más graves de la indiferencia es la normalización y aceptación de la violencia; es decir, el asumir que es normal que algunas personas, debido a sus cargos políticos, su ocupación profesional, su ideología y/o clase social, hayan sido o sean el objetivo de ETA» (27). La Patria, en consecuencia, se convierte en el objetivo supremo que anula el dolor ajeno y permite marginar las opiniones encontradas para imponer una visión unívoca de la realidad que alienta y justifica el uso de la violencia. A la indiferencia subyacente a esta situación hacen frente las cuestiones a las que 
aspira a dar respuesta esta investigación: "ipuede ser la cultura un herramienta para despertar una imaginación ética que cambie el modo en que concebimos al semejante, el modo en que vivimos en esa sociedad?» y, de modo más específico, «¿es posible potenciar una imaginación que nos haga pasar de la indiferencia a una actitud de compromiso con la reparación?» (2829). Convencida de que la cultura no sólo puede alimentar la imaginación, sino también la conciencia crítica del individuo ante su entorno, Portela se lanza al análisis de obras literarias, fílmicas y fotográficas, sin ocultarnos nunca cuál es su posición personal.

La reflexión se centra en primer lugar en la figura del testigo y en la posibilidad que ofrecen sus elaboraciones imaginativas en las obras de ficción para «entender la complejidad y la variedad de puntos de vista con los que acercarnos a este conflicto» (41). Porque el testigo no está libre de cargas ideológicas, y además tiene un punto de vista individual, una experiencia vital y un conocimiento de la sociedad que pueden ofrecernos nuevas posiciones desde las que tratar de comprender los distintos matices de ese silencio. Los documentos culturales que interesan a la autora son aquellos que a través de un proceso cognoscitivo aspiran a desvelar y, sobre todo, a dar a conocer distintos aspectos de la sociedad vasca para que los receptores se vean obligados a cuestionarse, a ponerse en posiciones ideológicas y vitales divergentes. Por esa razón, escoge dos documentales que han tenido una recepción complicada, pues su objetivo es entender el entorno y los agentes que participan y conviven con la violencia. Asier ETA biok, de Aitor Merino y Echevarriatik Etxeberriara. Oiartzun: Indarkeriarekin bizi izan den herri baten kronikak, de Ander Iriarte, abordan esta cuestión desde la cercanía afectiva pero sin renunciar a la crítica y sin omitir ni las contradicciones ni los sinsentidos de muchos de los relatos de los participantes en estos documentales. Si Merino centra su atención en Asier, amigo y miembro de ETA recién salido de la cárcel, con quien mantiene una estrecha relación, no exenta de extrañeza e incomprensión ante quien es incapaz de cuestionarse su rol como violento, la búsqueda de conocimiento como respuesta a la incomodidad de ese testigo que se niega a ser cómplice conduce a Iriarte a un documental que parte de lo íntimo para adentrarse en lo colectivo, la vivencia de la violencia por parte de los habitantes de Oiartzun, su lugar de origen. No sólo la complejidad de las posturas en conflicto ocupan un primer plano, sino que estas obras articulan un discurso poliédrico que no ahorra al espectador ni los contrastes ni las discordancias que derivan de la vida diaria de una sociedad contaminada por las visiones unívocas del mundo. 
El rigor, la inteligencia y la capacidad crítica con que la autora encara estos primeros análisis marcará la línea reflexiva del resto del texto, pero también asentará las razones por las que son ciertas obras (y no otras) las que centran una investigación en continua tensión.

Los silencios, sus identidades y sus rupturas, así como su relación con el lenguaje y los discursos que nos imponen realidades, constituyen las claves de la segunda parte del Eco de los disparos. Consciente de que «cuando forzamos al lenguaje a representar una visión unívoca de la realidad, la capacidad de comunicación propia se pierde» (67), Portela propone en este capítulo el análisis de creaciones literarias y fílmicas que han utilizado la expresividad del mutismo para contrarrestar las imposiciones de significado que derivan de discursos totalitarios que han contaminado la comunicación en la sociedad vasca. Que el «silencio tiene en sí mismo muchos significados» y que estos pueden ser absolutamente divergentes se hace evidente a lo largo del análisis de algunos relatos de Jokin Muñoz, José Manuel Fajardo y Ángel Lertxundi, y películas tan diferentes como Ocho apellidos vascos de Emilio Martínez Lázaro, Negociador de Borja Cobeaga y Tiro en la cabeza de Jaime Rosales.

El silencio traza en estas obras multitud de matices, precisamente porque «plantea un panorama de complicada interpretación, debido tanto a la variedad de los motivos y mecanismos por los cuales aparece como por su difícil representación en artefactos culturales» (72). Precisamente la autora escoge estas obras porque muestran cómo ese silencio obsesivo y asfixiante que ha caracterizado a la sociedad vasca ha funcionado como modo de vida al amparo de la violencia, pero también como estrategia de negación o de convivencia fallida; ha servido como forma de resistencia, pero también como imposición de los fanáticos que promueven un discurso unívoco que margina voces divergentes; subraya que puede funcionar como cómplice del discurso dominante, caldo de cultivo del odio y la indiferencia, pero también puede ser escudo protector ante el ataque; y, finalmente, subraya cómo ha servido como signo de una supuesta «normalización» tras el alto al fuego de ETA, aunque también constituya una evidencia de que en la representación de la violencia y de sus consecuencias todavía quedan muchos aspectos por tratar que, por precipitación o por una necesidad de seguir adelante, parecemos querer olvidar. Este fragmento insiste en el rigor del análisis y pone de manifiesto la voluntad sostenida de Portela por no caer en juicios fáciles y rápidamente consumibles, y, sobre todo, confirma su apuesta por un arte incómodo, difícil, que nos enfrente a sucesos y a lenguajes que 
no encajen con nuestra visión del mundo, pues es desde ahí «desde donde deberíamos iniciar la conversación sobre nuestra participación en la historia reciente» (94) y la reformulación de nuestra cosmovisón.

La representación ficcional de víctimas y perpetradores de la violencia centra el último capítulo, adentrándose así en un terrenos peligroso en ambos extremos: ni el diluir estas categorías y ni el convertirlas en un otro intocable e impermeable puede contribuir a ampliar la imaginación de una sociedad que ha sido testigo y cómplice. La autora está convencida de que es necesario analizar estas representaciones para entender cómo forman parte de nuestra configuración social y abordar estereotipos inamovibles (el de la víctima) o simplificados como mera encarnación del Mal (en el caso del verdugo). La búsqueda de otros sitios desde los cuales mirar y, sobre todo, la ruptura del tabú de inhumanidad por parte de Clemente Bernard, un fotoperiodista que aborda la multiplicidad del conflicto y poniéndonos ante la tesitura de tener que reflexionar sobre «el derecho a representar a la víctima y al perpetrador, sobre las formas que hay de representarlos y dónde están los límites actuales de esa representación» (143), nos enfrentan a la dificultad de recepción, individual y colectiva, de tales obras. Precisamente son las narraciones que ponen al receptor ante una percepción ética de las consecuencias del "conflicto», o que lo enfrentan a su visión habitualmente maniquea, las que dan continuidad a esa indagación. Los relatos de Iban Zaldua, Harkaitz Cano y Eider Rodríguez, entre otros, y la película La casa de mi padre de Gorka Merchán desequilibran nuestras asunciones y prejuicios por medio de narraciones espinosas que desestabilizan una visión compartimentada de la realidad. No sólo reflejan la hondura y la continuidad de los daños causados por la violencia en las víctimas, también nos recuerdan algo que tal vez en nuestro afán por simplificar preferimos ignorar: cómo la sociedad ha jerarquizado a las víctimas en función de su cercanía o afinidad, ignorando voluntariamente la magnitud de la violencia y el alcance de sus consecuencias. Frente a los relatos que cuestionan nuestras certidumbres, Portela sitúa otros, los que nos ubican lejos del perpetrador y nos facilitan la incomprensión de sus procesos, tranquilizándonos al trazar con claridad las líneas que delimitan los territorios del bien y del mal. A estas narraciones, que contribuyen a la condena rotunda tanto de ETA y de su entorno como de quienes se sitúan en el extremo contrario, el del Estado y sus excesos, Portela les reconoce el valor de crear historias verosímiles, pero cuestiona su capacidad para ensanchar nuestro conocimiento del mundo y de 
interpelarnos en nuestras cómodas posiciones.

Las representaciones artísticas y las rememoraciones autobiográficas y colectivas sirven a la autora para analizar cómo ha afectado a la sociedad vasca la convivencia con la violencia durante décadas, pero también para proponer y reivindicar un cambio en nuestra imaginación ética, un viraje que amplíe nuestro conocimiento y haga posible un acercamiento a los otros, dejando a un lado sus posiciones identitarias e ideológicas. La necesidad de la incomodidad y la incertidumbre como motores del conocimiento y el cambio, y el rol que la cultura ocupa en esa dinámica, aluden a una sociedad que no puede conformarse ni con el olvido ni con la simplificación. Ampliar la imaginación a partir de la dimensión íntima es una propuesta de futuro para la sociedad vasca, a la que la cultura tiene que contribuir convirtiéndose en un acto arriesgado que nos haga cuestionarnos, que nos conviertan en vulnerables, porque desde esa posición «tal vez podamos entender la vulnerabilidad del otro, mirarle a los ojos y verlo» (207).

El libro de Edurne Portela es un dispositivo engañoso, en el buen sentido de la palabra. Sus memorias íntimas, sus análisis y argumentaciones analizan el presente y el pasado, pero siempre proyectándose hacia un futuro que alude insistentemente a un lector, transformando la recepción en una cuestión tan personal como lo es el propio texto. Una de las claves de este libro es que deja poco espacio a la indiferencia y más cuando el lector comparte con la autora elementos biográficos definitorios. La intrahistoria y la Historia de la que nos habla son compartidas por muchos de los que leemos y leeremos un texto que más que documento generacional, es una llamada al compromiso social, a la necesidad de que miremos con otros ojos, liberándonos de nuestros prejuicios y nuestros dogmas ideológicos, aquello que el arte puede ofrecernos: conocer al otro, dialogar con él, construir juntos un futuro de más comunicación y menos violencia. Este ensayo heterodoxo se propone como primer paso para un nuevo tipo de análisis cultural, perspicaz y sosegado, que cuestione lo que miramos y también cómo y desde dónde lo hacemos. Portela elude entrar en el análisis de autores que podrían estar entre sus objetivos, lo que supone cierto lastre para su análisis, pues podría darle un alcance mucho mayor. Por otro lado, apuesta por poner bajo la lupa a otros autores u obras no tan centrales, revisando no sólo las interpretaciones que se han formulado sino también los prejuicios desde los que han surgido. En todo caso, nos deberíamos quedar con que este texto, crítico y lúcido hasta las últimas consecuencias, ofrece significativas aportaciones: nos invita a recorrer nuevos 
caminos críticos, caminos que nos sacan de la Academia y nos ponen a pie de calle; nos recuerda (por si desde nuestra actual visión cientifista y utilitarista lo hemos olvidado) que el arte cumple funciones destacadas en la sociedad, como mostrarnos aspectos, situaciones y vivencias que podrían explicarnos mejor cómo es nuestro mundo; nos implica cultural y socialmente en la reflexión que la sociedad vasca debe encarar sobre las décadas que han estado marcadas por la violencia; y nos invita, en definitiva, a seguir atentos a ese futuro colectivo en el que tanto nos jugamos y que debería estar libre de las cargas del silencio y de los relatos hegemónicos. 